\title{
Dynamics of a Beddington-DeAngelis Type Predator-Prey Model with Impulsive Effect
}

\author{
Sun Shulin ${ }^{1}$ and Guo Cuihua ${ }^{2}$ \\ ${ }^{1}$ School of Mathematics and Computer Science, Shanxi Normal University, Linfen, Shanxi 041004, China \\ ${ }^{2}$ School of Mathematical Science, Shanxi University, Taiyuan, Shanxi 030006, China
}

Correspondence should be addressed to Sun Shulin; sunshulin2013@163.com

Received 21 September 2013; Accepted 13 November 2013

Academic Editor: Nasser Saad

Copyright (C) 2013 S. Shulin and G. Cuihua. This is an open access article distributed under the Creative Commons Attribution License, which permits unrestricted use, distribution, and reproduction in any medium, provided the original work is properly cited.

In view of the logical consistence, the model of a two-prey one-predator system with Beddington-DeAngelis functional response and impulsive control strategies is formulated and studied systematically. By using the Floquet theory of impulsive equation, small amplitude perturbation method, and comparison technique, we obtain the conditions which guarantee the global asymptotic stability of the two-prey eradication periodic solution. We also proved that the system is permanent under some conditions. Numerical simulations find that the system appears the phenomenon of competition exclusion.

\section{Introduction}

In an ecological system, understanding the dynamical relationships between predator and prey is one of the central goals. One important component of the predator-prey relationships is the predator's functional response. Functional response refers to the change in the density of prey attached per unit time per predator as the prey density changes. In 1965, Holling [1] gave three different kinds of functional response for different kinds of species to model the phenomena of predation, which made the standard LotkaVolterra system more realistic. The Beddington-DeAngelis functional response was introduced by Beddington [2] and DeAngelis et al. [3] in 1975. It is similar to the Holling type functional response but contains an extra term describing mutual interference by predators. Thus, a predator-prey model with Beddington-DeAngelis functional response is as the following form $[2,3]$ :

$$
\begin{gathered}
\frac{d x(t)}{d t}=a x(t)\left(1-\frac{x(t)}{K}\right)-\frac{e x(t) y(t)}{b y(t)+x(t)+c}, \\
\frac{d y(t)}{d t}=-D y(t)+\frac{\operatorname{mex}(t) y(t)}{b y(t)+x(t)+c},
\end{gathered}
$$

where $x(t)$ and $y(t)$ represent the population density of the prey and the predator at time $t$, respectively. Usually, $K$ is called the carrying capacity of the prey. The constant $a$ is called intrinsic growth rate of the prey. $m$ is the conversion rate and $D$ is the death rate of the predator. The term $b y(t)$ measures the mutual interference between predators. In 2004, Fan and Kuang [4] explored the dynamics of the nonautonomous, spatially homogeneous, and continuous time predator-prey system with the Beddington-DeAngelis functional response. The explorations involved the permanence, extinction, and global asymptotic stability (general nonautonomous case); the existence, uniqueness, and stability of a positive (almost) periodic solution; and a boundary (almost) periodic solution for the periodic (almost periodic) case.

It is straightforward to generalize the above two-species model to the situation when two prey species competing for the same resource but the two prey species are predated by one predator species. This results in the following threespecies model:

$$
\begin{aligned}
\frac{d x(t)}{d t} & =a_{1} x(t)\left(1-\frac{x(t)+y(t)}{K}\right)-\frac{e_{1} x(t) z(t)}{b_{1} z(t)+x(t)+c_{1}}, \\
\frac{d y(t)}{d t} & =a_{2} y(t)\left(1-\frac{x(t)+y(t)}{K}\right)-\frac{e_{2} y(t) z(t)}{b_{2} z(t)+y(t)+c_{2}}, \\
\frac{d z(t)}{d t} & =-D z(t)+\frac{m_{1} e_{1} x(t) z(t)}{b_{1} z(t)+x(t)+c_{1}}+\frac{m_{2} e_{2} y(t) z(t)}{b_{2} z(t)+y(t)+c_{2}} .
\end{aligned}
$$


If $x$ and $y$ are identical species, then $a_{1}=a_{2}=a, e_{1}=$ $e_{2}=e, b_{1}=b_{2}=b, c_{1}=c_{2}=c$, and $m_{1}=m_{2}=m$. Let $N=x+y$; then, the model that is consistent with (2) should take the form

$$
\begin{gathered}
\frac{d N(t)}{d t}=a N(t)\left(1-\frac{N(t)}{K}\right)-\frac{e N(t) z(t)}{b z(t)+N(t)+c}, \\
\frac{d z(t)}{d t}=-D z(t)+\frac{m e N(t) z(t)}{b z(t)+N(t)+c} .
\end{gathered}
$$

If model (2) is logically sound one, it should reduce itself to (3) in this situation. However, the result is not the case; instead, it becomes

$$
\begin{gathered}
\frac{d N(t)}{d t}=a N(t)\left(1-\frac{N(t)}{K}\right) \\
-\frac{e x(t) z(t)}{b z(t)+x(t)+c}-\frac{e y(t) z(t)}{b z(t)+y(t)+c}, \\
\frac{d z(t)}{d t}=-D z(t)+\frac{\operatorname{mex}(t) z(t)}{b z(t)+x(t)+c}+\frac{\operatorname{mey}(t) z(t)}{b z(t)+y(t)+c} .
\end{gathered}
$$

According to the logical consistence proposed by Arditi and Michalski in 1996 [5], a logically consistent model of the two-prey one-predator interaction should take the form

$$
\begin{aligned}
\frac{d x(t)}{d t}= & a_{1} x(t)\left(1-\frac{x(t)+y(t)}{K}\right) \\
& -\frac{e_{1} x(t) z(t)}{b_{1} z(t)+x(t)+y(t)+c_{1}}, \\
\frac{d y(t)}{d t}= & a_{2} y(t)\left(1-\frac{x(t)+y(t)}{K}\right) \\
& -\frac{e_{2} y(t) z(t)}{b_{2} z(t)+x(t)+y(t)+c_{2}},
\end{aligned}
$$

$$
\begin{aligned}
\frac{d z(t)}{d t}= & -D z(t)+\frac{m_{1} e_{1} x(t) z(t)}{b_{1} z(t)+x(t)+y(t)+c_{1}} \\
& +\frac{m_{2} e_{2} y(t) z(t)}{b_{2} z(t)+x(t)+y(t)+c_{2}} .
\end{aligned}
$$

There are a number of factors in the environment to be considered in predator-prey models. One of the important factors is an impulsive perturbation such as fire and flood; these are not suitable to be considered continuously. The impulsive perturbations bring sudden changes to the system. Let us think of prey as a pest and predator as a natural enemy of prey. There are many ways to beat agricultural pests, for example, biological control such as harvesting on prey and releasing natural enemies [6-11] and chemical control such as spreading pesticides. However, integrated pest management (IPM) is a more effective approach to control pests in farm, which has been proved by experiments (see [1214]). Such tactics are discontinuous and periodical. With the idea of periodic forcing and impulsive perturbations, Baek [15] has investigated the predator-prey model with periodic constant impulsive immigration of the predator and periodic variation in the intrinsic growth rate of the prey. And an ecological model consisting of two preys and one predator with impulsive release of the predator is studied in [16]. In this paper, we will consider an ecological model consisting of two preys and one predator with impulsive control strategy. We give some assumptions as follows.

(H1) Two prey species compete the same resource.

(H2) Functional response is effected for mutual interference by predators.

Thus, the model can be described by the following impulsive differential equations:

$$
\begin{aligned}
& \left.\begin{array}{l}
\frac{d x(t)}{d t}=a_{1} x(t)\left(1-\frac{x(t)+y(t)}{K}\right)-\frac{e_{1} x(t) z(t)}{b_{1} z(t)+x(t)+y(t)+c_{1}}, \\
\frac{d y(t)}{d t}=a_{2} y(t)\left(1-\frac{x(t)+y(t)}{K}\right)-\frac{e_{2} y(t) z(t)}{b_{2} z(t)+x(t)+y(t)+c_{2}},
\end{array}\right\} t \neq n T, \\
& \frac{d z(t)}{d t}=-D z(t)+\frac{m_{1} e_{1} x(t) z(t)}{b_{1} z(t)+x(t)+y(t)+c_{1}}+\frac{m_{2} e_{2} y(t) z(t)}{b_{2} z(t)+x(t)+y(t)+c_{2}}, \\
& x\left(t^{+}\right)=\left(1-p_{1}\right) x(t), \\
& y\left(t^{+}\right)=\left(1-p_{2}\right) y(t), \quad t=n T \text {, } \\
& z\left(t^{+}\right)=\left(1-p_{3}\right) z(t)+q \\
& \left(x\left(0^{+}\right), y\left(0^{+}\right), z\left(0^{+}\right)\right)=\left(x_{0}, y_{0}, z_{0}\right)=\mathbf{X}_{0} \text {, }
\end{aligned}
$$

where $x(t), y(t)$, and $z(t)$ are the densities of the two preys and a predator at time $t$, respectively. $K$ is the total carrying capacity of two prey species; $a_{i}(i=1,2)$ are the intrinsic growth rate; $e_{i}(i=1,2)$ are the catching rate; $b_{i}(i=1,2)$ scale the impact of predators mutual interference; $c_{i}(i=1,2)$ are saturation constants; $m_{i}(i=1,2)$ denote the efficiency with which resources are converted to new consumers; $D$ is the mortality rate of the predator. $T$ is the period of the impulsive effect; $n \in N ; N$ is the set of all nonnegative integers; $p_{i}(i=1,2,3)$ represent the fractions of prey and predator which die due to pesticides; $q$ is the release amount of the predator at $t=n T$. 
The paper is arranged as follows. In Section 2, we give some notations and lemmas. In Section 3, we consider the local stability and global asymptotic stability of the twoprey eradication periodic solution by using Floquet theory of the impulsive equation, small amplitude perturbation, and techniques of comparison, and in Section 4 we show that the system is permanent. The paper ends with some interesting numerical simulations and conclusions.

\section{Preliminaries}

Firstly, we give some notations, definitions, and lemmas which will be useful for our main results.

Let $R_{+}=[0,+\infty), R_{+}^{3}=\left\{X=(x, y, z) \in R^{3} \mid x \geqslant\right.$ $0, y \geqslant 0, z \geqslant 0\}$. Denoted by $f=\left(f_{1}, f_{2}, f_{3}\right)^{T}$ the map defined by the right hand of the former three equations in system (6) and denoted by $N$ the set of all nonnegative integers. Let $V: R_{+} \times R_{+}^{3} \rightarrow R_{+}$; then, $V$ is said to belong to class $V_{0}$ if

(1) $V$ is continuous in $(n T,(n+1) T] \times R_{+}^{3}$ and, for each $X \in R_{+}^{3}, n \in N, \lim _{(t, y) \rightarrow\left(n T^{+}, X\right)} V(t, y)=V\left(n T^{+}, X\right)$ exists;

(2) $V$ is locally Lipschitzian in $X$;

Definition 1. Let $V \in V_{0}$; then, for $(t, X) \in(n T,(n+1) T] \times$ $R_{+}^{3}$, the upper right derivative of $V(t, X)$ with respect to the impulsive differential system (6) is defined as

$$
\begin{aligned}
D^{+} V(t, X)= & \lim _{h \rightarrow 0^{+}} \sup \frac{1}{h} \\
& \times[V(t+h, X+h f(t, X))-V(t, X)] .
\end{aligned}
$$

The solution of system (6) is a piecewise continuous function $X: R_{+} \rightarrow R_{+}^{3}, X(t)$ is continuous on $(n T,(n+1) T]$, $n \in N$, and $X\left(n T^{+}\right)=\lim _{t \rightarrow n T^{+}} X(t)$ exists. The smoothness properties of $f$ guarantee the global existence and uniqueness of solution of system (6) (see [17] for the details).

Definition 2. System (6) is said to be permanent if there exists a compact $\Omega \subset \operatorname{Int} R_{+}^{3}$ such that every solution $(x(t), y(t), z(t))$ of system (6) will eventually enter and remain in the region $\Omega$.

The following lemma is obvious.

Lemma 3. Let $X(t)$ be a solution of system (6) with $X\left(0^{+}\right) \geqslant 0$; then, $X(t) \geqslant 0$ for all $t \geqslant 0$. And, furthermore, $X(t)>0, t>0$ if $X\left(0^{+}\right)>0$.

We will use an important comparison theorem on impulsive differential equation.

Lemma 4 (comparison theorem [17]). Suppose $V \in V_{0}$. Assume that

$$
\begin{array}{cc}
D^{+} V(t, X) \leq g(t, V(t, X)), & t \neq n T, \\
V\left(t, X\left(t^{+}\right)\right) \leq \psi_{n}(V(t, X)), & t=n T,
\end{array}
$$

where $g: R_{+} \times R_{+} \rightarrow R$ is continuous in $(n T,(n+1) T] \times R_{+}$ and, for $u \in R_{+}, n \in N, \lim _{(t, v) \rightarrow\left(n T^{+}, u\right)} g(t, v)=g\left(n T^{+}, u\right)$ exists and $\psi_{n}: R_{+} \rightarrow R_{+}$is nondecreasing. Let $r(t)$ be the maximal solution of the scalar impulsive differential equation

$$
\begin{gathered}
\frac{d u(t)}{d t}=g(t, u(t)), \quad t \neq n T, \\
u\left(t^{+}\right) \leq \psi_{n}(u(t)), \quad t=n T, \\
u\left(0^{+}\right)=u_{0},
\end{gathered}
$$

existing on $[0,+\infty]$. Then, $V\left(0^{+}, X_{0}\right) \leqslant u_{0}$ implies that $V(t, X(t)) \leqslant r(t)$ for all $t \geqslant 0$, where $X(t)$ is any solution of system (6).

To research the stability of the prey-free periodic solution of (6), we present the Floquet theory for the linear $T$-periodic impulsive equations:

$$
\begin{gathered}
\frac{d X(t)}{d t}=A(t) X(t), \quad t \neq \tau_{k}, \quad t \in R, \\
X\left(t^{+}\right)=\left(E+B_{k}\right) X(t), \quad t=\tau_{k}, k \in \mathbb{Z} .
\end{gathered}
$$

Then, we introduce the following conditions.

$(\mathrm{H} 2.1) A(\cdot) \in P C\left(R, C^{n \times n}\right)$ and $A(t+T)=A(t),(t \in$ $R$ ), where $P C\left(R, C^{n \times n}\right)$ is the set of all piecewise continuous matrix functions which is left continuous at $t=\tau_{k}$ and $C^{n \times n}$ is the set of all $n \times n$ matrices.

(H2.2) $B_{k} \in C^{n \times n}, \operatorname{det}\left(E+B_{k}\right) \neq 0$, and $\tau_{k}<\tau_{k+1}$.

(H2.3) There exists a $q \in \mathbb{N}$ such that $B_{k+q}=B_{k}, \tau_{k+q}=\tau_{k}+T$, and $k \in \mathbb{Z}$.

Let $\Phi(t)$ be a fundamental matrix of (10); then, there exists a unique nonsingular matrix $M \in C^{n \times n}$ such that

$$
\Phi(t+T)=\Phi(t) M, \quad(t \in R)
$$

For this equality, we call the constant matrix $M$ is the monodromy matrix of (10) (corresponding to the fundamental matrix $\Phi(t))$

All monodromy matrices of (10) are similar and have the same eigenvalues. The eigenvalues $\mu_{1}, \ldots, \mu_{n}$ of the monodromy matrices are called the Floquet multipliers of (10).

Lemma 5 (Floquet theory [18]). Let conditions (H2.1)-(H2.3) hold. Then, the linear T-periodic impulsive equation (10) is

(1) stable if and only if all multipliers $\mu_{j}(j=1, \ldots, n)$ of (10) satisfy the inequality $\left|\mu_{j}\right| \leq 1$, and, moreover, to those $\mu_{j}$, for which $\left|\mu_{j}\right|=1$, correspond simple elementary divisors;

(2) asymptotically stable if and only if all multipliers $\mu_{j}(j=1, \ldots, n)$ of $(10)$ satisfy the inequality $\left|\mu_{j}\right|<1$;

(3) unstable if $\left|\mu_{j}\right|>1$ for some $j=1, \ldots, n$. 
Now, one gives some basic properties about the following subsystem of system (6):

$$
\begin{gathered}
\frac{d z(t)}{d t}=-D z(t), \quad t \neq n T, \\
z\left(t^{+}\right)=\left(1-p_{3}\right) z(t)+q, \quad t=n T, \\
z\left(0^{+}\right)=z_{0} .
\end{gathered}
$$

Then we can easily obtain the following results.

Lemma 6. (1) $z^{*}(t)=q \exp (-D(t-n T)) /(1-(1-$ $\left.\left.p_{3}\right) \exp (-D T)\right), t \in(n T,(n+1) T], n \in N$, and $z^{*}\left(0^{+}\right)=$ $q /\left(1-\left(1-p_{3}\right) \exp (-D T)\right)$ is a positive periodic solution of $(12)$.

(2) $z(t)=\left(1-p_{3}\right)^{n}\left(z_{0}-(q /(1-(1-\right.$ $\left.\left.\left.\left.p_{3}\right) \exp (-D T)\right)\right)\right) \exp (-D t)+z^{*}(t)$ is the solution of (12) with $z_{0} \geqslant 0, t \in(n T,(n+1) T]$, and $n \in N$.

(3) All solutions $z(t)$ of (12) with $z_{0} \geqslant 0$ tend to $z^{*}(t)$. That is, $\left|z(t)-z^{*}(t)\right| \rightarrow 0$ as $t \rightarrow \infty$.

Therefore, we obtain the complete expression for the two-prey eradication periodic solution $\left(0,0, z^{*}(t)\right)$ of system (6). We will study the stability of the two-prey eradication periodic solution of system (6) in the next section.

\section{Prey Eradication Periodic Solution}

Firstly, we show that all solutions of (6) are uniformly ultimately bounded.

Theorem 7. There exists a constant $M>0$, such that $x(t) \leqslant$ $M, y(t) \leqslant M, z(t) \leqslant M$ for all $t$ large enough, where $(x(t), y(t), z(t))$ is a solution of system (6).

Proof. Define $V(t, X(t))$ such that

$$
V(t, X(t))=m_{1} x(t)+m_{2} y(t)+z(t)
$$

then, $V \in V_{0}$. We calculate the upper right derivative of $V(t, X)$ along a solution of system (6) and get the following impulsive differential inequality:

$$
\begin{aligned}
& D^{+} V(t)+L V(t) \\
& \leqslant\left(a_{1}+L\right) m_{1} x(t) \\
& \quad-\frac{a_{1} m_{1}}{K} x^{2}(t)+\left(a_{2}+L\right) m_{2} y(t) \\
& \quad-\frac{a_{2} m_{2}}{K} y^{2}(t)+(L-D) z(t), \quad t \neq n T, \\
& \quad V\left(t^{+}\right) \leqslant V(t)+q, \quad t=n T .
\end{aligned}
$$

Let $0<L<D$; then, $D^{+} V(t)+L V(t)$ is bounded. Select $L_{1}$ and $L_{2}$ such that

$$
\begin{gathered}
D^{+} V(t) \leq-L_{1} V(t)+L_{2}, \quad t \neq n T, \\
V\left(t^{+}\right) \leq V(t)+q, \quad t=n T,
\end{gathered}
$$

where $L_{1}$ and $L_{2}$ are two positive constants.
According to Lemma 4, we have

$$
\begin{aligned}
V(t) \leqslant & \left(V\left(0^{+}\right)-\frac{L_{2}}{L_{1}}\right) \exp \left(-L_{1} t\right) \\
& +\frac{q\left(1-\exp \left(-n L_{1} T\right)\right)}{1-\exp \left(-L_{1} T\right)} \exp \left(-L_{1}(t-n T)\right)+\frac{L_{2}}{L_{1}}
\end{aligned}
$$

where $t \in(n T,(n+1) T]$. Therefore, $V(t, X(t))$ is ultimately bounded by a constant and there exists a constant $M>0$, such that $x(t) \leqslant M, y(t) \leqslant M, z(t) \leqslant M$ for all $t$ large enough. The proof is completed.

Now, we study the stability of the two-prey eradication periodic solution of system (6).

Theorem 8. Let $(x(t), y(t), z(t))$ be any solution of system (6); then, $\left(0,0, z^{*}(t)\right)$ is said to be locally asymptotically stable if

$$
\begin{aligned}
a_{1} T+ & \frac{e_{1}}{D b_{1}} \ln \left[1-\frac{b_{1} q(1-\exp (-D T))}{c_{1}\left(1-\left(1-p_{3}\right) \exp (-D T)\right)+b_{1} q}\right] \\
& <\ln \frac{1}{1-p_{1}}, \\
a_{2} T+ & \frac{e_{2}}{D b_{2}} \ln \left[1-\frac{b_{2} q(1-\exp (-D T))}{c_{2}\left(1-\left(1-p_{3}\right) \exp (-D T)\right)+b_{2} q}\right] \\
& <\ln \frac{1}{1-p_{2}} .
\end{aligned}
$$

Proof. The local stability of periodic solution $\left(0,0, z^{*}(t)\right)$ may be determined by considering the behavior of small amplitude perturbation of the solution. Define

$$
\begin{gathered}
x(t)=u(t), \quad y(t)=v(t), \\
z(t)=w(t)+z^{*}(t) .
\end{gathered}
$$

Putting (18) into (6), the linearization of the system becomes

$$
\begin{aligned}
& \left.\begin{array}{rl}
\frac{d u(t)}{d \mathrm{t}} & =\left(a_{1}-\frac{e_{1} z^{*}(t)}{b_{1} z^{*}(t)+c_{1}}\right) u(t), \\
\frac{d v(t)}{d t} & =\left(a_{2}-\frac{e_{2} z^{*}(t)}{b_{2} z^{*}(t)+c_{2}}\right) v(t), \\
\frac{m_{1} e_{1} z^{*}(t)}{b_{1} z^{*}(t)+c_{1}} u(t)+\frac{m_{2} e_{2} z^{*}(t)}{b_{2} z^{*}(t)+c_{2}} v(t)-D w(t),
\end{array}\right\} t \neq n T, \\
& \left.\begin{array}{rl}
u\left(t^{+}\right) & =\left(1-p_{1}\right) u(t), \\
v\left(t^{+}\right) & =\left(1-p_{2}\right) v(t),
\end{array}\right\} t=n T . \\
& w\left(t^{+}\right)=\left(1-p_{3}\right) w(t),
\end{aligned}
$$

Therefore, we have

$$
\left(\begin{array}{c}
u(t) \\
v(t) \\
w(t)
\end{array}\right)=\Phi(t)\left(\begin{array}{c}
u(0) \\
v(0) \\
w(0)
\end{array}\right), \quad 0 \leqslant t<T,
$$


where $\Phi(t)$ satisfies

$$
\frac{d \Phi}{d t}=\left(\begin{array}{ccc}
a_{1}-\frac{e_{1} z^{*}(t)}{b_{1} z^{*}(t)+c_{1}} & 0 & 0 \\
0 & a_{2}-\frac{e_{2} z^{*}(t)}{b_{2} z^{*}(t)+c_{2}} & 0 \\
\frac{m_{1} e_{1} z^{*}(t)}{b_{1} z^{*}(t)+c_{1}} & \frac{m_{2} e_{2} z^{*}(t)}{b_{2} z^{*}(t)+c_{2}} & -D
\end{array}\right) \Phi(t)
$$

$\Phi(0)=I$, the identity matrix, and

$$
\left(\begin{array}{c}
u\left(n T^{+}\right) \\
v\left(n T^{+}\right) \\
w\left(n T^{+}\right)
\end{array}\right)=\left(\begin{array}{ccc}
1-p_{1} & 0 & 0 \\
0 & 1-p_{2} & 0 \\
0 & 0 & 1-p_{3}
\end{array}\right)\left(\begin{array}{c}
u(n T) \\
v(n T) \\
w(n T)
\end{array}\right) .
$$

The stability of the periodic solution $\left(0,0, z^{*}(t)\right)$ is determined by the eigenvalues of

$$
\Theta=\left(\begin{array}{ccc}
1-p_{1} & 0 & 0 \\
0 & 1-p_{2} & 0 \\
0 & 0 & 1-p_{3}
\end{array}\right) \Phi(T) .
$$

If absolute values of all eigenvalues are less than one, then the periodic solution $\left(0,0, z^{*}(t)\right)$ is locally asymptotically stable. All eigenvalues of $\Theta$ are as follows:

$$
\begin{gathered}
\mu_{1}=\left(1-p_{1}\right) \exp \left(\int_{0}^{T}\left(a_{1}-\frac{e_{1} z^{*}(t)}{b_{1} z^{*}(t)+c_{1}}\right) d t\right), \\
\mu_{2}=\left(1-p_{2}\right) \exp \left(\int_{0}^{T}\left(a_{2}-\frac{e_{2} z^{*}(t)}{b_{2} z^{*}(t)+c_{2}}\right) d t\right), \\
\mu_{3}=\left(1-p_{3}\right) \exp (-D T)<1 .
\end{gathered}
$$

According to the Floquet theory of impulsive differential equation, $\left(0,0, z^{*}(t)\right)$ is locally asymptotically stable if $\left|\mu_{1}\right|<$ 1 and $\left|\mu_{2}\right|<1$; that is to say,

$$
\begin{aligned}
a_{1} T+ & \frac{e_{1}}{D b_{1}} \ln \left[1-\frac{b_{1} q(1-\exp (-D T))}{c_{1}\left(1-\left(1-p_{3}\right) \exp (-D T)\right)+b_{1} q}\right] \\
& <\ln \frac{1}{1-p_{1}}, \\
a_{2} T+ & \frac{e_{2}}{D b_{2}} \ln \left[1-\frac{b_{2} q(1-\exp (-D T))}{c_{2}\left(1-\left(1-p_{3}\right) \exp (-D T)\right)+b_{2} q}\right] \\
& <\ln \frac{1}{1-p_{2}} .
\end{aligned}
$$

This completes the proof.

Theorem 9. Let $(x(t), y(t), z(t))$ be any solution of system (6); then, $\left(0,0, z^{*}(t)\right)$ is said to be globally asymptotically stable if the conditions of Theorem 8 hold and

$$
\begin{aligned}
q \geqslant \max & \left\{\frac{a_{1}}{e_{1}}\left(\exp (D T)-\left(1-p_{3}\right)\right)\left(b_{1} M+2 M+c_{1}\right),\right. \\
& \left.\frac{a_{2}}{e_{2}}\left(\exp (D T)-\left(1-p_{3}\right)\right)\left(b_{2} M+2 M+c_{2}\right)\right\} .
\end{aligned}
$$

Proof. By Theorem 8, we know that $\left(0,0, z^{*}(t)\right)$ is locally asymptotically stable. In the following, we will prove its global attraction. Let $V(t)=x(t)+y(t)$; then, we get

$$
\begin{aligned}
\left.V^{\prime}\right|_{(1.6)}= & a_{1} x(t)-\frac{a_{1}}{K} x(t)(x(t)+y(t)) \\
& -\frac{e_{1} x(t) z(t)}{b_{1} z(t)+x(t)+y(t)+c_{1}} \\
& +a_{2} y(t)-\frac{a_{2}}{K} y(t)(x(t)+y(t)) \\
& -\frac{e_{2} y(t) z(t)}{b_{2} z(t)+x(t)+y(t)+c_{2}} .
\end{aligned}
$$

By Theorem 7, there exists a constant $M>0$, such that $x(t) \leqslant M, y(t) \leqslant M$, and $z(t) \leqslant M$ for each solution $X(t)=(x(t), y(t), z(t))$ of system (6) with all $t$ large enough.

Thus,

$$
\begin{aligned}
\left.V^{\prime}\right|_{(1.6)} \leqslant & a_{1} x(t)-\frac{e_{1} x(t) z(t)}{b_{1} M+2 M+c_{1}} \\
& +a_{2} y(t)-\frac{e_{2} y(t) z(t)}{b_{2} M+2 M+c_{2}} .
\end{aligned}
$$

On the other hand, we have

$$
\begin{aligned}
\frac{d z(t)}{d t}= & \frac{m_{1} e_{1} x(t) z(t)}{b_{1} z(t)+x(t)+y(t)+c_{1}} \\
& +\frac{m_{2} e_{2} y(t) z(t)}{b_{2} z(t)+x(t)+y(t)+c_{2}} \\
& -D z(t) \\
\geqslant & -D z(t), \quad t \neq n T, \\
z\left(t^{+}\right)= & \left(1-p_{3}\right) z(t)+q, \quad t=n T .
\end{aligned}
$$

By Lemmas 4 and 5, we know that there exists a $t_{1}>0$, and $\epsilon>0$ small enough, such that $z(t) \geqslant z^{*}(t)-\epsilon$; for all $t \geqslant t_{1}$, we have

$$
z(t) \geqslant \frac{q \exp (-D T)}{1-\left(1-p_{3}\right) \exp (-D T)}-\epsilon \triangleq \gamma .
$$

Then,

$$
\begin{aligned}
\left.V^{\prime}\right|_{(6)} \leqslant & \left(a_{1}-\frac{e_{1} \gamma}{b_{1} M+2 M+c_{1}}\right) x(t) \\
& +\left(a_{2}-\frac{e_{2} \gamma}{b_{2} M+2 M+c_{2}}\right) y(t),
\end{aligned}
$$

if $Q_{1} \triangleq a_{1}-\left(e_{1} \gamma /\left(b_{1} M+2 M+c_{1}\right)\right)<0$ and $Q_{2} \triangleq a_{2}-$ $\left(e_{2} \gamma /\left(b_{2} M+2 M+c_{2}\right)\right)<0$; that is to say,

$$
\begin{aligned}
q \geqslant \max & \left\{\frac{a_{1}}{e_{1}}\left(\exp (D T)-\left(1-p_{3}\right)\right)\left(b_{1} M+2 M+c_{1}\right),\right. \\
& \left.\frac{a_{2}}{e_{2}}\left(\exp (D T)-\left(1-p_{3}\right)\right)\left(b_{2} M+2 M+c_{2}\right)\right\} .
\end{aligned}
$$


Then, for $t \geqslant t_{1}$, we have

$$
\left.V^{\prime}\right|_{(6)} \leqslant-Q V(t),
$$

where $Q=\min \left\{\left|Q_{1}\right|,\left|Q_{2}\right|\right\}$, so $V(t) \rightarrow 0$ and $x(t) \rightarrow$ $0, y(t) \rightarrow 0$ as $t \rightarrow \infty$. Notice that the limit system of the system (6) is exactly as system (10); together with Lemma 5, we know that the two-prey eradication periodic solution $\left(0,0, z^{*}(t)\right)$ is a global attractor. The proof is completed.

\section{Permanence}

In this section, we investigate the permanence of the system (6).

Theorem 10. The system (6) is permanent if

$$
\begin{aligned}
& a_{1} T+ \frac{e_{1}}{D b_{1}} \ln \left[1-\frac{b_{1} q(1-\exp (-D T))}{c_{1}\left(1-\left(1-p_{3}\right) \exp (-D T)\right)+b_{1} q}\right] \\
&> \ln \frac{1}{1-p_{1}}, \\
& a_{2} T+ \frac{e_{2}}{D b_{2}} \ln \left[1-\frac{b_{2} q(1-\exp (-D T))}{c_{2}\left(1-\left(1-p_{3}\right) \exp (-D T)\right)+b_{2} q}\right] \\
&> \ln \frac{1}{1-p_{2}}, \\
& q \leq \max \left\{\frac{a_{1}}{e_{1}}\left(\exp (D T)-\left(1-p_{3}\right)\right)\left(b_{1} M+2 M+c_{1}\right),\right. \\
&\left.\frac{a_{2}}{e_{2}}\left(\exp (D T)-\left(1-p_{3}\right)\right)\left(b_{2} M+2 M+c_{2}\right)\right\} .
\end{aligned}
$$

Proof. Let $X(t)=(x(t), y(t), z(t))$ be any solution of the system (6) with $X(0)>0$. From Theorem 7, we assume that $x(t) \leqslant M, y(t) \leqslant M, z(t) \leqslant M$, and $M>$ $\max \left\{a_{1} c_{1} / e_{1}, a_{2} c_{2} / e_{2}\right\}$. Let $\zeta_{3}=(q \exp (-D T)) /(1-(1-$ $\left.\left.p_{3}\right) \exp (-D T)\right)-\epsilon, \epsilon>0$. From Lemma 5, clearly, we have $z(t) \geqslant \zeta_{3}$ for all $t$ large enough. Now, we will find $\bar{\zeta}_{1}$ and $\bar{\zeta}_{2}$ such that $x(t) \geqslant \bar{\zeta}_{1}$ and $y(t) \geqslant \bar{\zeta}_{2}$ for $t$ large enough. We will do this in the following two steps.

Step 1. We will prove that there exists a $t_{1} \in(0,+\infty)$ such that $x\left(t_{1}\right) \geqslant \zeta_{1}$. Otherwise, $x(t)<\zeta_{1}$ for all $t>0$.

We can choose $\zeta_{1}>0, \epsilon_{1}>0$ to be small enough such that

$$
\begin{gathered}
\delta=\frac{e_{1} a_{1} \zeta_{1}}{b_{1}}+\frac{e_{2} a_{2} M}{b_{2}}<D \\
\eta=\left(1-p_{1}\right) \exp \left(\int _ { n T } ^ { ( n + 1 ) T } \left(a_{1}\left(1-\frac{2 M}{K}\right)\right.\right. \\
\left.\left.-\frac{e_{1}\left(v^{*}(t)+\epsilon_{1}\right)}{c_{1}}\right) d t\right)>1 .
\end{gathered}
$$

From system (6), we can obtain that

$$
\begin{gathered}
\frac{d z(t)}{d t} \leqslant(-D+\delta) z(t), \quad t \neq n T, \\
z\left(t^{+}\right)=\left(1-p_{3}\right) z(t)+q, \quad t=n T, \\
z\left(0^{+}\right)=z_{0} .
\end{gathered}
$$

By Lemma 4 , we have $z(t) \leqslant v(t)$ and $v(t) \rightarrow v^{*}(t)$ as $t \rightarrow$ $+\infty$, where $v(t)$ is the solution of

$$
\begin{gathered}
\frac{d v(t)}{d t}=(-D+\delta) v(t), \quad t \neq n T, \\
v\left(t^{+}\right)=\left(1-p_{3}\right) v(t)+q, \quad t=n T, \\
v\left(0^{+}\right)=z_{0},
\end{gathered}
$$

and $v^{*}(t)=q \exp ((-D+\delta)(t-n T)) /\left(1-\left(1-p_{3}\right) \exp ((-D+\right.$ $\delta) T)), t \in(n T,(n+1) T]$, and $n \in N$. Therefore, there exists a $T_{1}>0$; when $t>T_{1}$, we have $z(t) \leqslant v(t)<v^{*}(t)+\epsilon_{1}$ and

$$
\begin{gathered}
\frac{d x(t)}{d t} \geqslant x(t)\left(a_{1}\left(1-\frac{2 M}{K}\right)-\frac{e_{1}\left(v^{*}(t)+\epsilon_{1}\right)}{c_{1}}\right), \quad t \neq n T, \\
x\left(t^{+}\right)=\left(1-p_{1}\right) x(t), \quad t=n T .
\end{gathered}
$$

Let $N_{1} \in N$ and $N_{1} T \geqslant T_{1}$; integrating (38) on $(n T,(n+1) T]$, $n \geqslant N_{1}$, we can obtain

$$
\begin{aligned}
& x((n+1) T) \\
& \geqslant x\left(n T^{+}\right) \\
& \quad \times \exp \left(\int _ { n T } ^ { ( n + 1 ) T } \left(a_{1}\left(1-\frac{2 M}{K}\right)\right.\right. \\
& \left.\left.=x(n T)\left(1-p_{1}\right) \quad-\frac{e_{1}\left(v^{*}(t)+\epsilon_{1}\right)}{c_{1}}\right) d t\right) \\
& \quad \times \exp \left(\int _ { n T } ^ { ( n + 1 ) T } \left(a_{1}\left(1-\frac{2 M}{K}\right)\right.\right. \\
& \left.\left.\quad-\frac{e_{1}\left(v^{*}(t)+\epsilon_{1}\right)}{c_{1}}\right) d t\right)
\end{aligned}
$$

$$
=x(n T) \eta \text {. }
$$

Then, $x\left(\left(N_{1}+k\right) T\right) \geqslant x\left(N_{1} T\right) \eta^{k} \rightarrow \infty$ as $k \rightarrow \infty$, which is a contradiction to the boundedness of $x(t)$. Hence, there exists a $t_{1}>0$ such that $x\left(t_{1}\right) \geqslant \zeta_{1}$.

Step 2. If $x(t) \geqslant \zeta_{1}$, for all $t \geqslant t_{1}$, then our aim is obtained. Hence, we only need to consider those solutions which leave the region $\Omega_{0}=\left\{x(t) \mid x(t)<\zeta_{1}\right\}$ and reenter it again. Letting $t^{*}=\inf _{t \geqslant t_{1}}\left\{x(t)<\zeta_{1}\right\}$, we have $x(t) \geqslant \zeta_{1}$ for $t \in\left[t_{1}, t^{*}\right]$; 


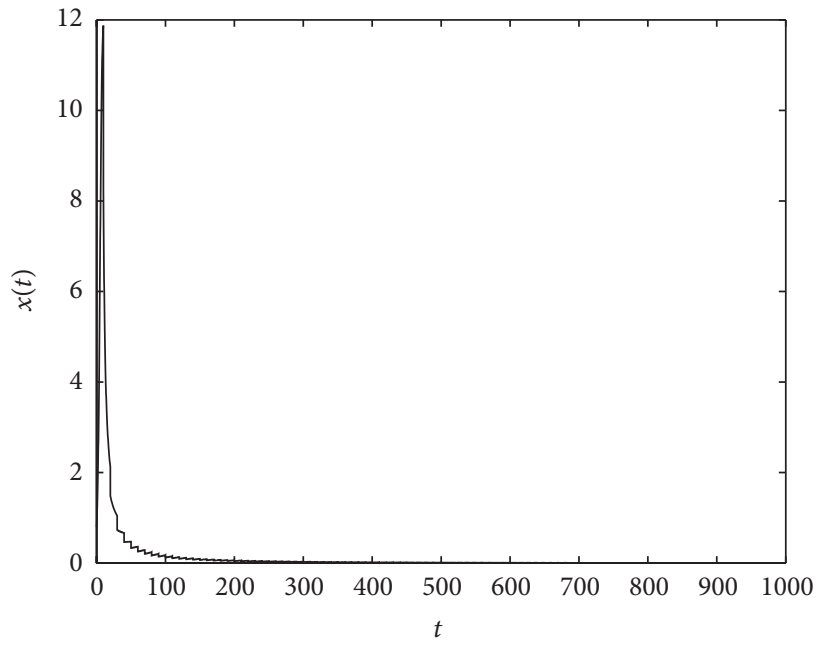

(a)

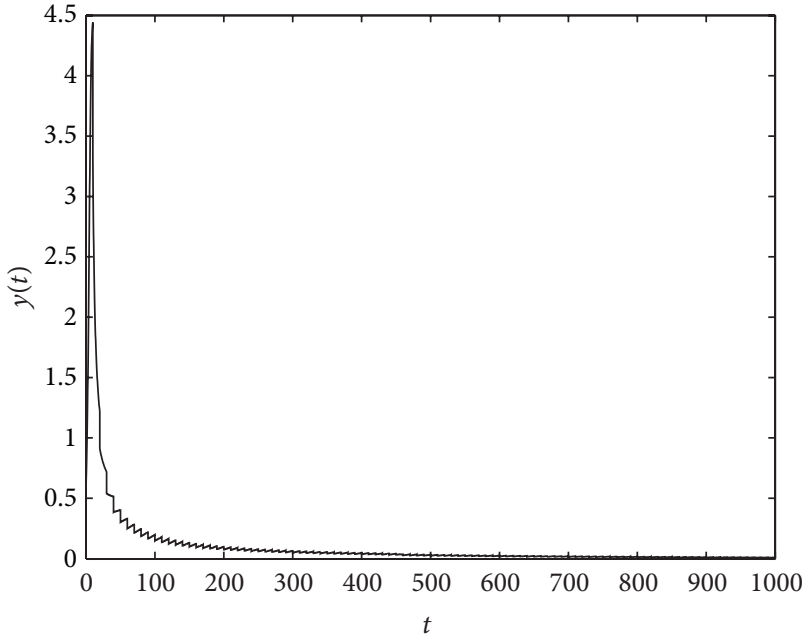

(b)

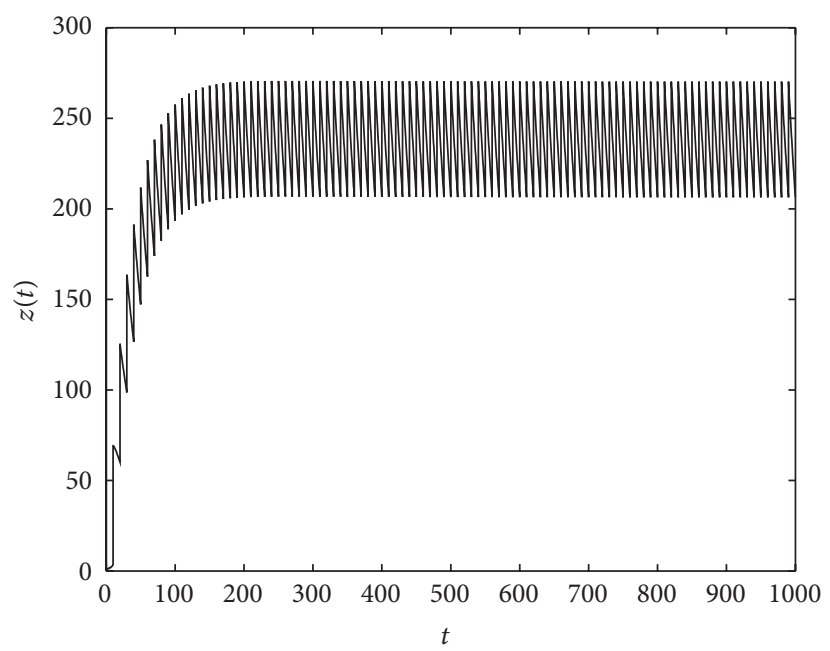

(c)

FIGURE 1: Time series of a solution of model (6) with $q=3.9$ : (a) time series of the prey population $x(t)$; (b) time series of the prey population $y(t) ;(\mathrm{c})$ time series of the predator population $z(t)$.

by the continuity of $x(t)$, we have $x\left(t^{*}\right)=\zeta_{1}$. In this step, we have only to consider two possible cases.

Case 1. $t^{*}=n_{1} T$ for some $n_{1} \in N$; then, $\left(1-p_{1}\right) \zeta_{1} \leqslant x\left(t^{*+}\right)=$ $\left(1-p_{1}\right) x\left(t^{*}\right)<\zeta_{1}$. Select $n_{2}, n_{3} \in N$ such that

$$
\begin{gathered}
n_{2} T>\frac{\ln \left(\epsilon_{1} /(M+q)\right)}{-D+\delta}, \\
\left(1-p_{1}\right)^{n_{2}} \exp \left(n_{2} \sigma T\right) \eta^{n_{3}} \\
>\left(1-p_{1}\right)^{n_{2}+1} \exp \left(\left(n_{2}+1\right) \sigma T\right) \eta^{n_{3}}>1,
\end{gathered}
$$

where $\sigma=a_{1}(1-(2 M / K))-\left(e_{1} \mathrm{M} / c_{1}\right)<0$. Let $T^{\prime}=n_{2} T+n_{3} T$. In this case, we will show that there exists $t_{2} \in\left(t^{*}, t^{*}+T^{\prime}\right]$ such that $x\left(t_{2}\right) \geqslant \zeta_{1}$; otherwise, $x(t)<\zeta_{1}$ for $t \in\left(t^{*}, t^{*}+T^{\prime}\right]$. Considering (37) with $v\left(t^{*+}\right)=z\left(t^{*+}\right)$, we have

$$
\begin{aligned}
v(t)= & \left(1-p_{3}\right)^{n-\left(n_{1}+1\right)} \\
& \times\left(v\left(t^{*+}\right)-\frac{q}{1-\left(1-p_{3}\right) \exp ((-D+\delta) T)}\right) \\
& \times \exp \left((-D+\delta)\left(t-t^{*}\right)\right)+v^{*}(t)
\end{aligned}
$$

for $(n-1) T<t \leqslant n T$ and $n_{1}+1 \leqslant n \leqslant n_{1}+1+n_{2}+n_{3}$; then,

$$
\begin{aligned}
&\left|v(t)-v^{*}(t)\right|<(M+q) \exp \left((-D+\delta)\left(t-t^{*}\right)\right) \\
&<(M+q) \exp \left((-D+\delta) n_{2} T\right)<\epsilon_{1}, \\
& z(t) \leqslant v(t) \leqslant v^{*}(t)+\epsilon_{1}
\end{aligned}
$$




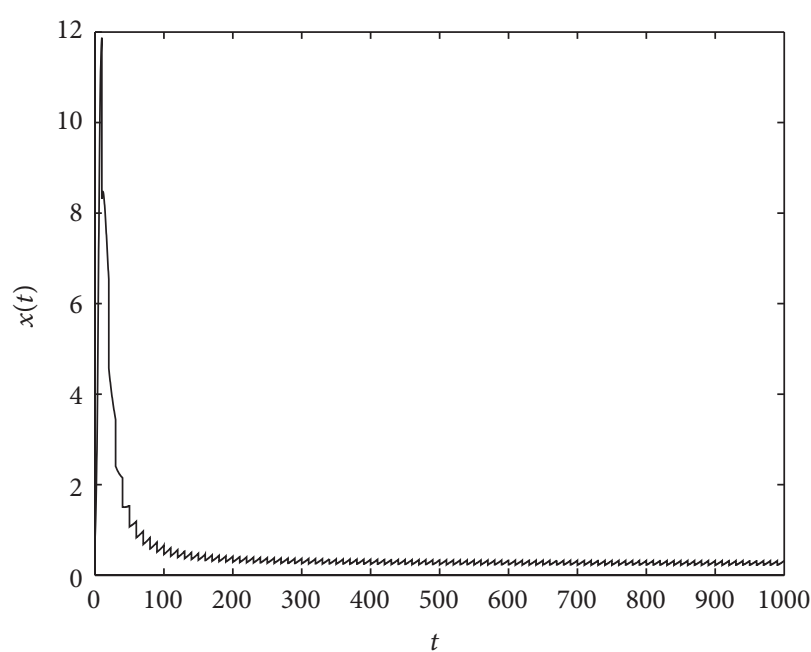

(a)

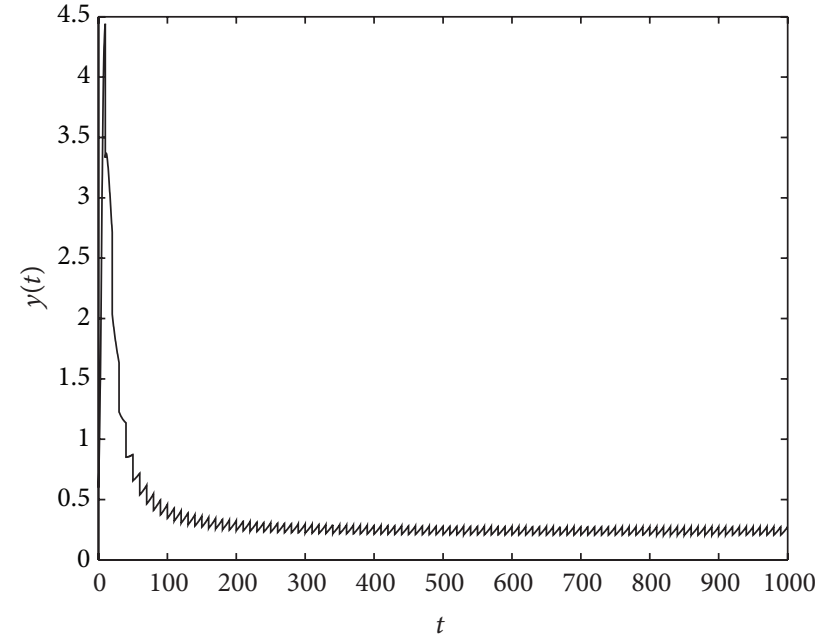

(b)

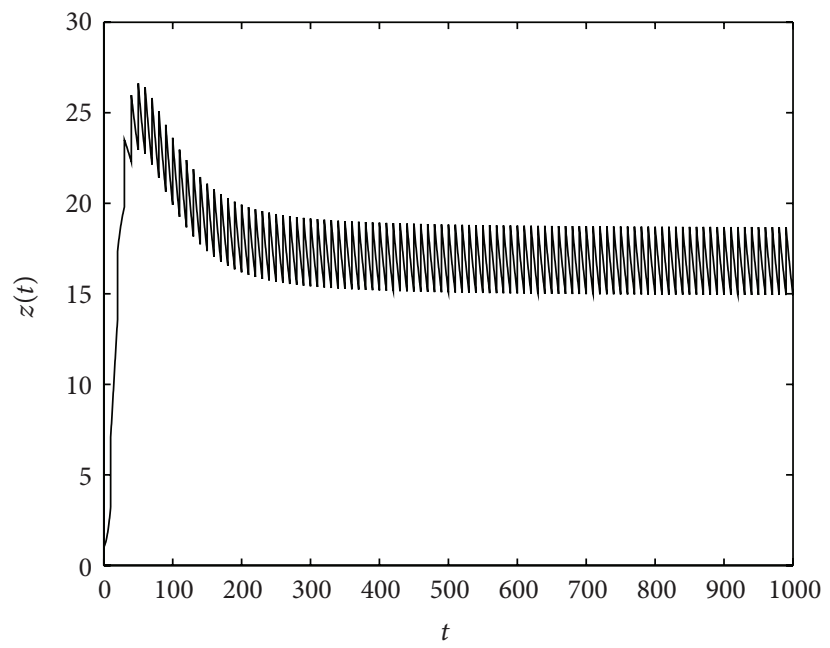

(c)

FIGURE 2: Time series of a solution of model (6) with $q=66$ : (a) time series of the prey population $x(t)$; (b) time series of the prey population $y(t)$; (c) time series of the predator population $z(t)$.

for $t^{*}+n_{2} T \leqslant t \leqslant t^{*}+T^{\prime}$, which implies that (38) holds for $t \in\left[t^{*}+n_{2} T, t^{*}+T^{\prime}\right]$. As in Step 1 , we have

$$
x\left(t^{*}+T^{\prime}\right) \geqslant x\left(t^{*}+n_{2} T\right) \eta^{n_{3}} .
$$

Since $z(t) \leqslant M$, we have

$$
\begin{gathered}
\frac{d x(t)}{d t} \geqslant x(t)\left(a_{1}\left(1-\frac{2 M}{K}\right)-\frac{e_{1} M}{c_{1}}\right)=\sigma x(t), \quad t \neq n T, \\
x\left(t^{+}\right)=\left(1-p_{1}\right) x(t), \quad t=n T,
\end{gathered}
$$

for $t \in\left[t^{*}, t^{*}+n_{2} T\right]$. Integrating (44) on $\left[t^{*}, t^{*}+n_{2} T\right]$, we have

$$
x\left(t^{*}+n_{2} T\right) \geqslant \zeta_{1}\left(1-p_{2}\right)^{n_{2}} \exp \left(\sigma n_{2} T\right) .
$$

Thus, $x\left(t^{*}+T^{\prime}\right) \geqslant \zeta_{1}\left(1-p_{2}\right)^{n_{2}} \exp \left(\sigma n_{2} T\right) \eta^{n_{3}}>\zeta_{1}$, which bring on a contradiction. Now, let $\bar{t}=\inf _{t \geqslant t^{*}}\left\{x(t) \geqslant \zeta_{1}\right\}$.
Then, $x(t) \leqslant \zeta_{1}$ for $t \in\left[t^{*}, \bar{t}\right)$ and $x(\bar{t})=\zeta_{1}$. For $t \in\left[t^{*}, \bar{t}\right)$, suppose that $t \in\left(t^{*}+(k-1) T, t^{*}+k T\right], k \in N$, and $k \leqslant n_{2}+n_{3}$; from (44), we obtain

$$
\begin{aligned}
x(t) \geqslant & x\left(t^{*+}\right)\left(1-p_{1}\right)^{k-1} \exp ((k-1) \sigma T) \\
& \times \exp \left(\sigma\left(t-\left(t^{*}+(k-1) T\right)\right)\right) \\
\geqslant & \zeta_{1}\left(1-p_{1}\right)^{k} \exp (k \sigma T) \\
\geqslant & \zeta_{1}\left(1-p_{1}\right)^{n_{2}+n_{3}} \exp \left(\sigma\left(n_{2}+n_{3}\right) T\right) \\
\equiv & \zeta_{1}^{\prime} .
\end{aligned}
$$

Case 2. $t^{*} \neq n T, n \in N$. Then, $x(t) \geqslant \zeta_{1}$ for $t \in\left[t_{1}, t^{*}\right)$ and $x\left(t^{*}\right)=\zeta_{1}$. Suppose that $t^{*} \in\left(n_{1}^{\prime} T,\left(n_{1}^{\prime}+1\right) T\right), n_{1}^{\prime} \in N$. There are two possible cases for $t \in\left(t^{*},\left(n_{1}^{\prime}+1\right) T\right]$. 


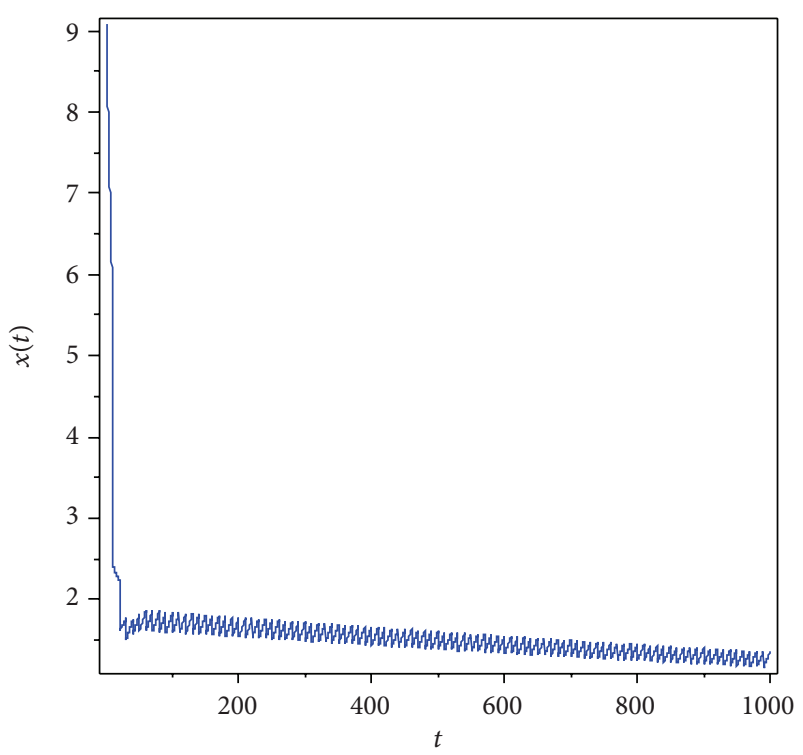

(a)

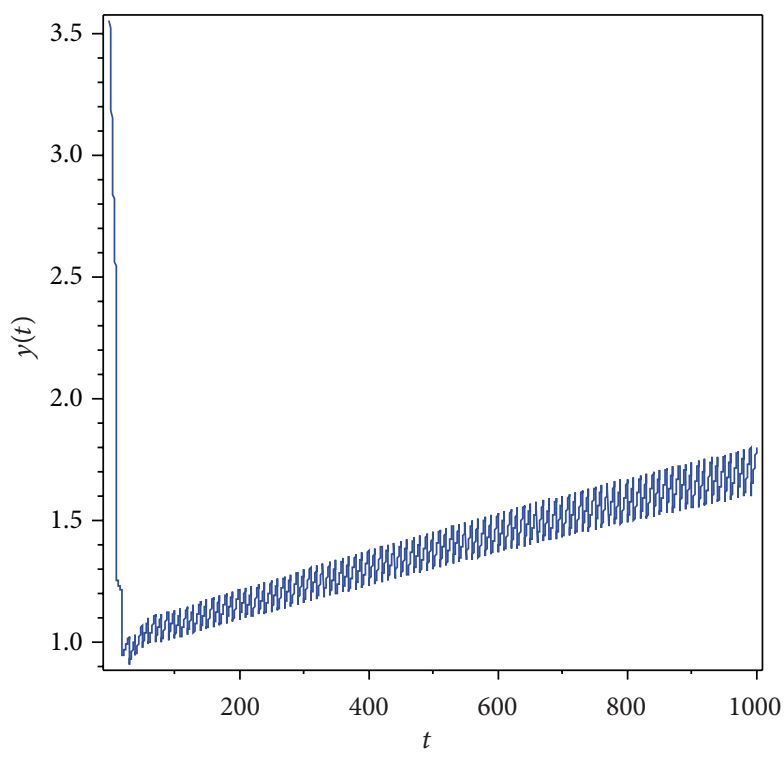

(b)

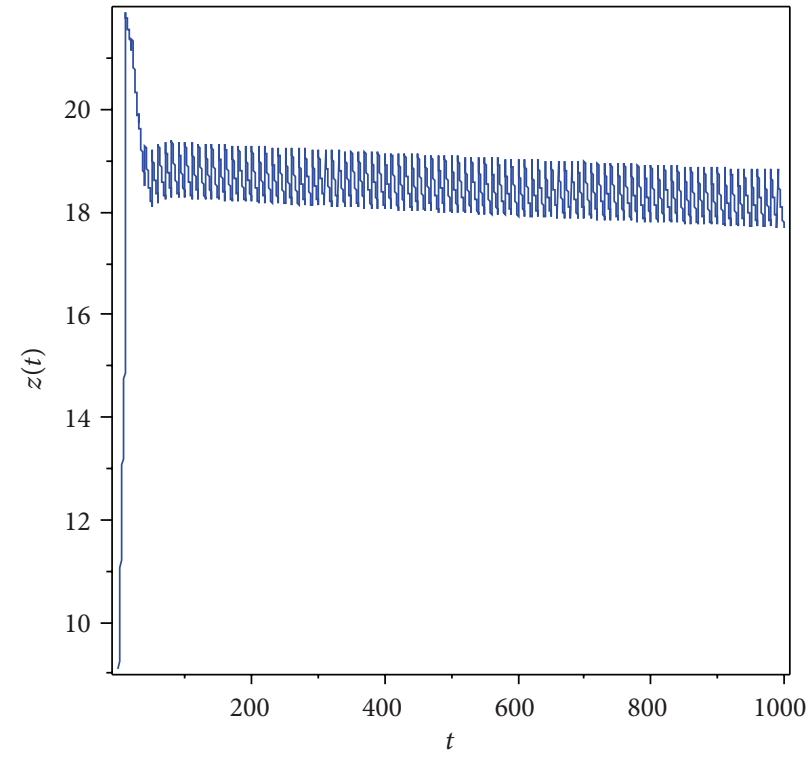

(c)

FIGURE 3: Time series of a solution of model (6) with $q=6$ : (a) time series of the prey population $x(t)$; (b) time series of the prey population $y(t)$; (c) time series of the predator population $z(t)$.

(a) $x(t)<\zeta_{1}$ for all $t \in\left(t^{*},\left(n_{1}^{\prime}+1\right) T\right]$. In this case, we will show that there exists $t_{2} \in\left[\left(n_{1}^{\prime}+1\right) T,\left(n_{1}^{\prime}+1\right) T+T^{\prime}\right]$ such that $x\left(t_{2}\right) \geqslant \zeta_{1}$. Otherwise, $x(t)<\zeta_{1}$ for all $t \in\left[\left(n_{1}^{\prime}+\right.\right.$ 1) $\left.T,\left(n_{1}^{\prime}+1\right) T+T^{\prime}\right]$. Then, $x(t)<\zeta_{1}$ for all $\left(t^{*},\left(n_{1}^{\prime}+1\right) T+T^{\prime}\right]$; considering (37) with $v\left(\left(n_{1}^{\prime}+1\right) T^{+}\right)=z\left(\left(n_{1}^{\prime}+1\right) T^{+}\right)$, we have

$$
\begin{aligned}
v(t)= & \left(1-p_{3}\right)^{n-\left(n_{1}^{\prime}+1\right)}\left(v\left(\left(n_{1}^{\prime}+1\right) T^{+}\right)\right. \\
& \left.-\frac{q}{1-\left(1-p_{3}\right) \exp ((-D+\delta) T)}\right) \\
& \times \exp \left((-D+\delta)\left(t-\left(n_{1}^{\prime}+1\right) T\right)\right)+v^{*}(t)
\end{aligned}
$$

for $n T<t \leqslant(n+1) T$ and $n_{1}^{\prime}+1 \leqslant n \leqslant n_{1}^{\prime}+1+n_{2}+n_{3}$. So we get

$$
\begin{aligned}
&\left|v(t)-v^{*}(t)\right|<(M+q) \\
& \times \exp \left((-D+\delta)\left(t-\left(n_{1}^{\prime}+1\right) T\right)\right) \\
&<(M+q) \exp \left((-D+\delta) n_{2} T\right)<\epsilon_{1}, \\
& z(t) \leqslant v(t) \leqslant v^{*}(t)+\epsilon_{1}
\end{aligned}
$$

for $\left(n_{1}^{\prime}+1+n_{2}\right) T \leqslant t \leqslant\left(n_{1}^{\prime}+1+n_{2}+n_{3}\right) T$, which implies that (38) holds for $t \in\left[\left(n_{1}^{\prime}+1+n_{2}\right) T,\left(n_{1}^{\prime}+1+n_{2}+n_{3}\right) T\right]$. As in Step 1, we have

$$
x\left(\left(n_{1}^{\prime}+1+n_{2}+n_{3}\right) T\right) \geqslant x\left(\left(n_{1}^{\prime}+1+n_{2}\right) T\right) \eta^{n_{3}} .
$$




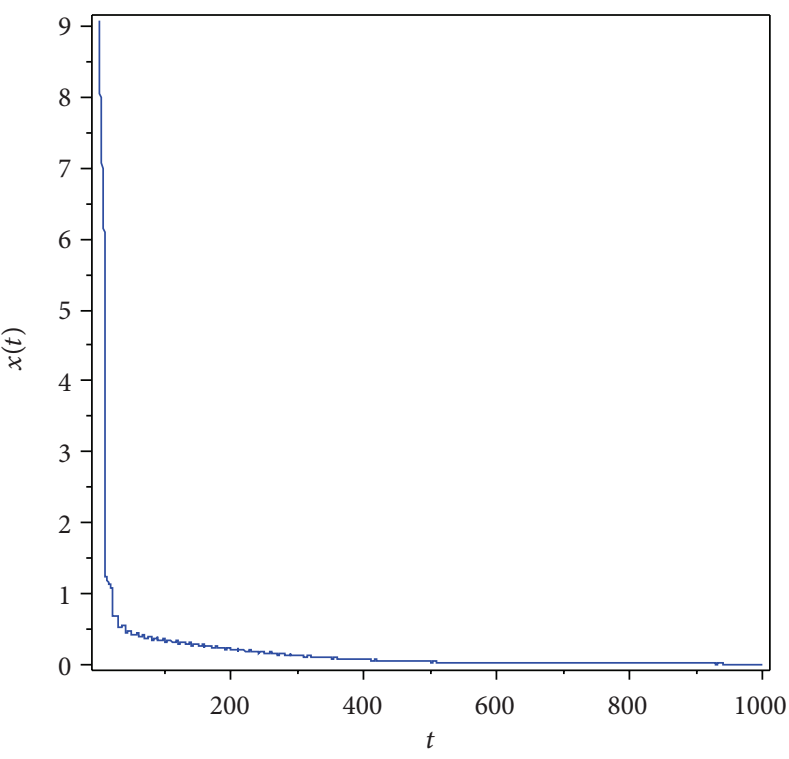

(a)

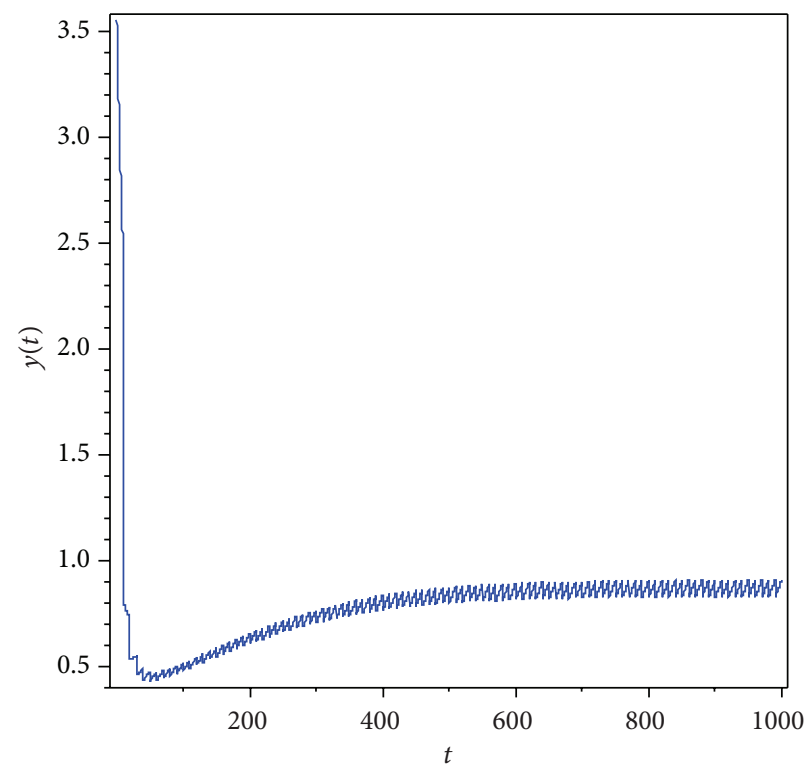

(b)

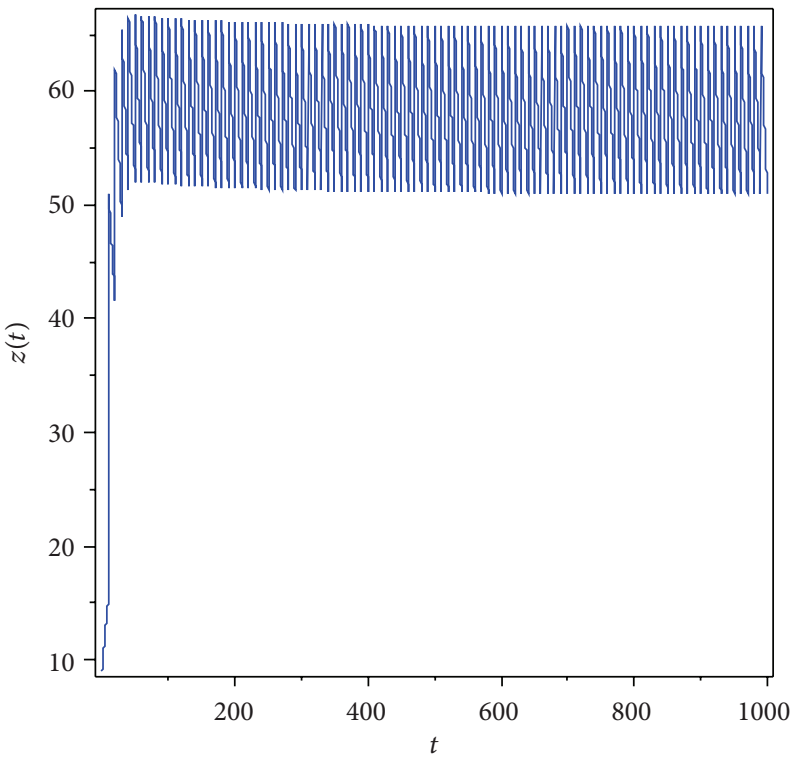

(c)

FIGURE 4: Time series of a solution of model (6) with $q=60$ : (a) time series of the prey population $x(t)$; (b) time series of the prey population $y(t)$; (c) time series of the predator population $z(t)$.

Integrate (44) on $\left(t^{*},\left(n_{1}^{\prime}+1+n_{2}\right) T\right)$, which yields

$$
x\left(\left(n_{1}^{\prime}+1+n_{2}\right) T\right) \geqslant \zeta_{1}\left(1-p_{1}\right)^{n_{2}+1} \exp \left(\sigma\left(n_{2}+1\right) T\right) .
$$

Thus, $x\left(\left(n_{1}^{\prime}+1+n_{2}+n_{3}\right) T\right) \geqslant \zeta_{1}\left(1-p_{1}\right)^{n_{2}+1} \exp \left(\sigma\left(n_{2}+\right.\right.$ 1)T) $\eta^{n_{3}}>\zeta_{1}$, which is a contradiction. Let $\bar{t}=\inf _{t \geqslant t^{*}}\{x(t) \geqslant$ $\left.\zeta_{1}\right\}$. Then, $x(t) \leqslant \zeta_{1}$ for $t \in\left[t^{*}, \bar{t}\right)$ and $x(\bar{t})=\zeta_{1}$. For $t \in\left[t^{*}, \bar{t}\right)$, suppose that $t \in\left(n_{1}^{\prime} T+\left(k^{\prime}-1\right) T, n_{1}^{\prime} T+k^{\prime} T\right], k^{\prime} \in N$, and $k^{\prime} \leqslant 1+n_{2}+n_{3}$; we have $x(t) \geqslant \zeta_{1}\left(1-p_{1}\right)^{n_{2}+n_{3}+1} \exp \left(\sigma\left(n_{2}+\right.\right.$ $\left.\left.n_{3}+1\right) T\right) \equiv \bar{\zeta}$. Since $\zeta^{\prime}>\bar{\zeta}$, so $x(t) \geqslant \bar{\zeta}$ for all $t \in\left(t^{*}, \bar{t}\right)$. (b) There exists $t_{3} \in\left(t^{*},\left(n_{1}^{\prime}+1\right) T\right]$ such that $x\left(t_{3}\right) \geqslant \zeta_{1}$. Let $\widehat{t}=\inf _{t \geqslant t^{*}}\left\{x(t) \geqslant \zeta_{1}\right\}$; then, $x(t) \leqslant \zeta_{1}$ for all $t \in\left[t^{*}, \widehat{t}\right)$ and $x(\hat{t})=\zeta_{1}$. Also, (44) holds for $t \in\left[t^{*}, \hat{t}\right)$. Integrating the equation on $\left[t^{*}, t\right)\left(t^{*} \leqslant t \leqslant \widehat{t}\right)$, we can get that $x(t) \geqslant$ $x\left(t^{*}\right) \exp \left(\sigma\left(t-t^{*}\right)\right) \geqslant \zeta_{1} \exp (\sigma T) \geqslant \bar{\zeta}$. Thus, in both cases, we conclude $x(t) \geqslant \bar{\zeta}$ for all $t \geqslant t_{1}$.

Similarly, we can prove $y(t) \geqslant \bar{\zeta}_{2}$ for all $t \geqslant t_{2}$.

Set $\Omega=\left\{(x(t), y(t), z(t)) \mid x(t) \geqslant \bar{\zeta}_{1}, y(t) \geqslant \bar{\zeta}_{2}, z(t) \geqslant\right.$ $\left.\zeta_{3}\right\}$. Obviously, we know that the set $\Omega \in \operatorname{Int} R_{+}^{3}$ is a global attractor; every solution of system (6) will eventually enter and remain in region $\Omega$. Therefore, system (6) is permanent. The proof is completed. 


\section{Numerical Simulations and Conclusions}

To study the dynamics of an ecological model consisting of two preys and one predator with impulsive control strategy, the solution of the system (6) with initial date $\left(x_{0}, y_{0}, z_{0}\right)=$ $(0.8,0.6,1)$ in the positive cone is obtained numerically for biologically feasible range of parametric value. In order to verify our theoretical results, let $a_{1}=0.8, a_{2}=0.6, K=20$, $e_{1}=0.844, e_{2}=0.647, m_{1}=0.25, m_{2}=0.2, b_{1}=1.1$, $b_{2}=1.13, c_{1}=0.06, c_{2}=0.05, D=0.027, p_{1}=0.3, p_{2}=0.25$, $p_{3}=0.01$ and $T=10$. On the other hand, it follows from Theorem 7 that we can select a positive number $M$. Thus, by a straightforward computation, we can obtain the two critical values $q^{*}=65.83$ and $q_{*}=3.98$. When $q=66>q^{*}$, it satisfies the condition of Theorem 9 , so the prey eradication periodic solution $\left(0,0, z^{*}(t)\right)$ is globally asymptotically stable, A type prey eradication periodic solution of the system (6) is shown in Figure 1, where we may observe how the variable $z(t)$ oscillates in a stable cycle. In contrast, the prey $x(t)$ and the prey $y(t)$ rapidly decrease to zero. When $q=3.9<q_{*}$, it satisfies the condition of Theorem 10, so the system (6) is permanent. That is to say, the preys and the predator can coexist (see Figure 2). Furthermore, we can give the other two critical values $q_{* *}=5.31$ and $q^{* *}=65.03$. When $q_{* *}<$ $q<q^{* *}$, it does not satisfy the conditions of Theorems 9 and 10 , but numerical simulations illustrate that the system (6) appears to be the principle of competition exclusion. That is to say, the competition between two prey populations give rise to the result that one prey becomes extinct and the other prey population is persisted. For example, letting $q=6$, the result is as in Figure 3; letting $q=60$, the result is in as Figure 4 .

In this paper, we have investigated effects of impulsive perturbations on a predator-prey model consisting of two preys and one predator with Beddington-DeAngelis functional response. By using the Floquet theorem and small amplitude perturbation skills, we have proved that the periodic solution $\left(0,0, z^{*}(t)\right)$ is globally asymptotically stable when the values of impulsive perturbation $q$ are greater than the critical value $q^{*}$. In addition, it has been shown that model (6) is permanent when the values of impulsive perturbation $q$ are less than the critical value $q_{*}$. By numerical simulations, we have found that the system (6) appears to be the principle of competition exclusion, when $q_{* *}<q<q^{* *}$. However, our model with the logical consistence is different from the model in [16]; that is, dynamic complexities in [16] does not appear in our model. Thus, our results suggest a new control approach which is more suitable than the classical one in the pest control.

\section{Acknowledgments}

This work is supported by the National Natural Science Foundation of China (no. 10771179) and the Natural Science Foundation of Shanxi Province (no. 2013011002-2).

\section{References}

[1] C. S. Holling, "The functional response of predator to prey density and its role in mimicry and population regulations,"
Memoirs of the Entomological Society of Canada, vol. 45, pp. 160, 1965.

[2] J. R. Beddington, "Mutual interference between parasites or predator and its effect on searching efficiency," Journal of Animal Ecology, vol. 44, pp. 331-340, 1975.

[3] D. L. DeAngelis, R. A. Goldstein, and R. V. O’Neill, "A model for trophic interaction," Ecology, vol. 56, pp. 881-892, 1975.

[4] M. Fan and Y. Kuang, "Dynamics of a nonautonomous predator-prey system with the Beddington-DeAngelis functional response," Journal of Mathematical Analysis and Applications, vol. 295, no. 1, pp. 15-39, 2004.

[5] R. Arditi and J. Michalski, "Nonlinear food web models and their response to increased basal productivity," in Food Webs: Integration of Patterns and Dynamics, A. G. Polis and K. O. Winemiller, Eds., pp. 122-133, Chapman and Hall, New York, NY, USA, 1996.

[6] H. J. Barclay, "Models for pest control using predator release, habitat management and pesticide release in combination," Journal of Applied Ecology, vol. 19, no. 2, pp. 337-348, 1982.

[7] H. I. Freedman, "Graphical stability, enrichment, and pest control by a natural enemy," Mathematical Biosciences, vol. 31, no. 3-4, pp. 207-225, 1976.

[8] J. Grasman, O. A. van Herwaarden, L. Hemerik, and J. C. van Lenteren, "A two-component model of host-parasitoid interactions: determination of the size of inundative releases of parasitoids in biological pest control," Mathematical Biosciences, vol. 169, no. 2, pp. 207-216, 2001.

[9] F. D. Parker, "Management of pest populations by manipulating densities of both host and parasites through periodic releases," in Biological Control, C. B. Huffaker, Ed., Plenum Press, New York, NY, USA, 1971.

[10] J. C. van Lenteren, "Measures of success in biological control of anthropoids by augmentation of natural enemies," in Measures of Success in Biology Control, S. Wratten and G. Gurr, Eds., Kluwer Academic, Dordrecht, The Netherlands, 2000.

[11] B. Liu, Y. Zhang, and L. Chen, "The dynamical behaviors of a Lotka-Volterra predator-prey model concerning integrated pest management," Nonlinear Analysis: Real World Applications, vol. 6, no. 2, pp. 227-243, 2005.

[12] J. C. van Lenteren, "Integrated pest management in protected crops," in Integrated Pest Management, D. Dent, Ed., Chapman and Hall, London, UK, 1995.

[13] University of California, Division of Agriculture and Natural Resources, Integrated Pest Management For Alfafa Hay, Publication 3312, Division of Agriculture and Natural Resources, University of California, Oakland, Calif, USA, 1981.

[14] M. L. Flint, Ed., Integrated Pest Management for Walnuts, Publication 3270, University of California, Oakland, Calif, USA, 2nd edition, 1987.

[15] H. K. Baek, "Qualitative analysis of Beddington-DeAngelis type impulsive predator-prey models," Nonlinear Analysis: Real World Applications, vol. 11, no. 3, pp. 1312-1322, 2010.

[16] H. Yu, S. Zhong, and R. P. Agarwal, "Mathematics and dynamic analysis of an apparent competition community model with impulsive effect," Mathematical and Computer Modelling, vol. 52, no. 1-2, pp. 25-36, 2010.

[17] V. Lakshmikantham, D. D. Bainov, and P. C. Simeonov, Theory of Impulsive Differential Equations, World Scientific, Singapore, 1989.

[18] D. D. Bainov and P. S. Simeonov, Differential Equations: Periodic Solutions and Applications, Longman Science and Technical, Harlo, UK, 1993. 


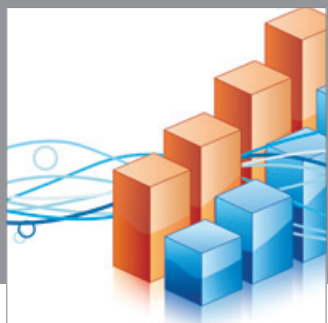

Advances in

Operations Research

mansans

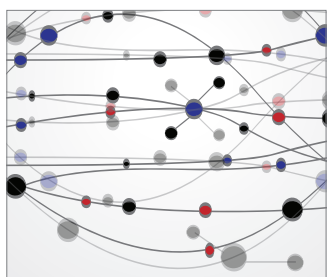

The Scientific World Journal
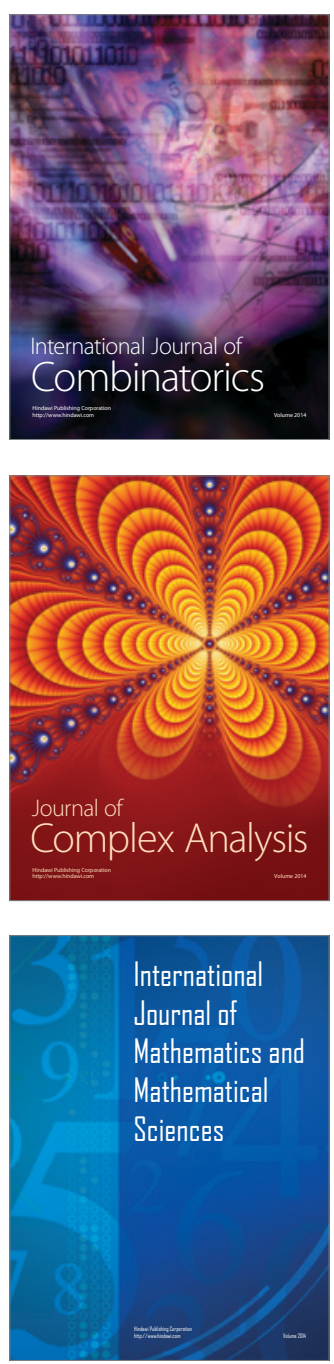
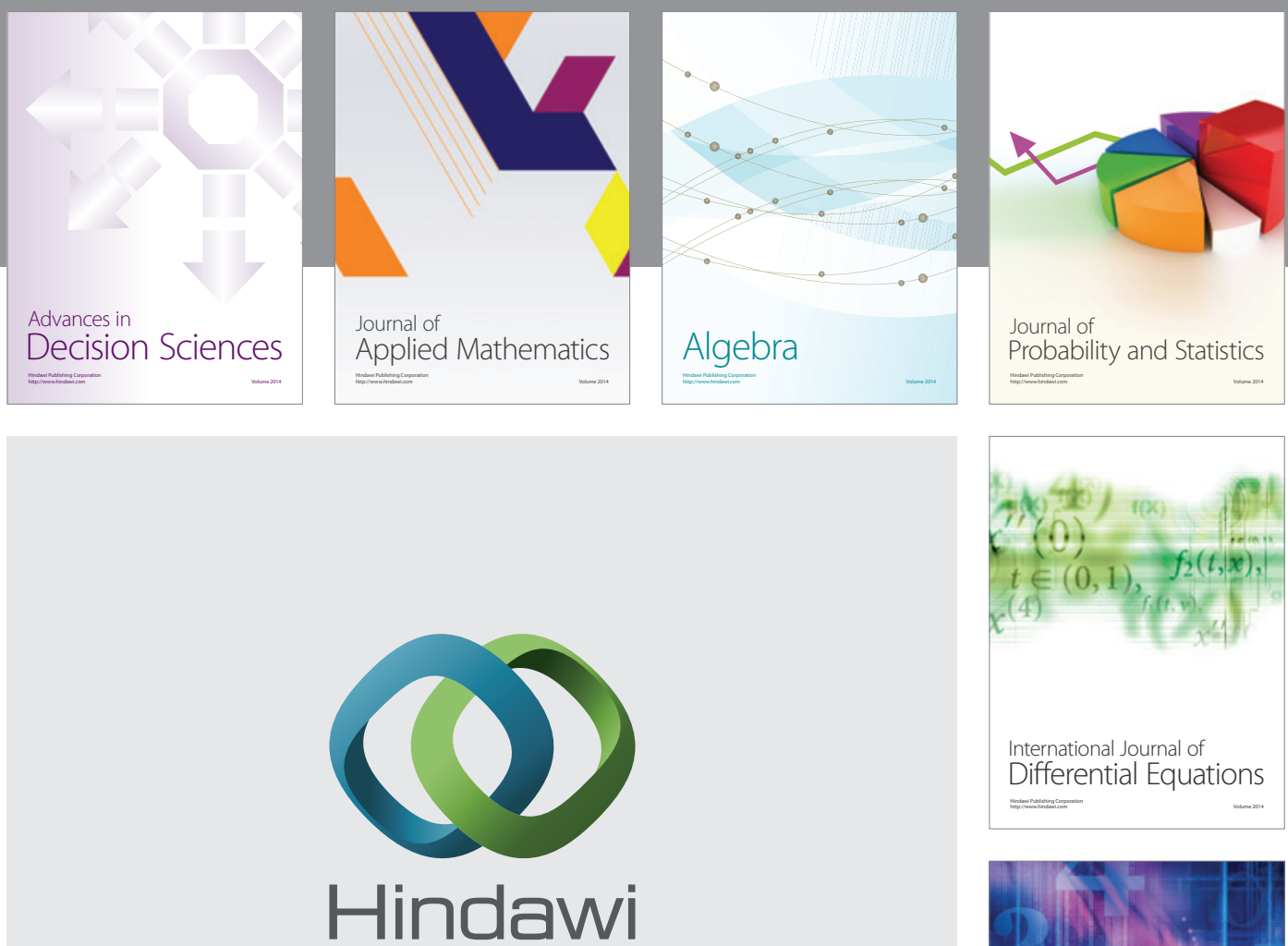

Submit your manuscripts at http://www.hindawi.com
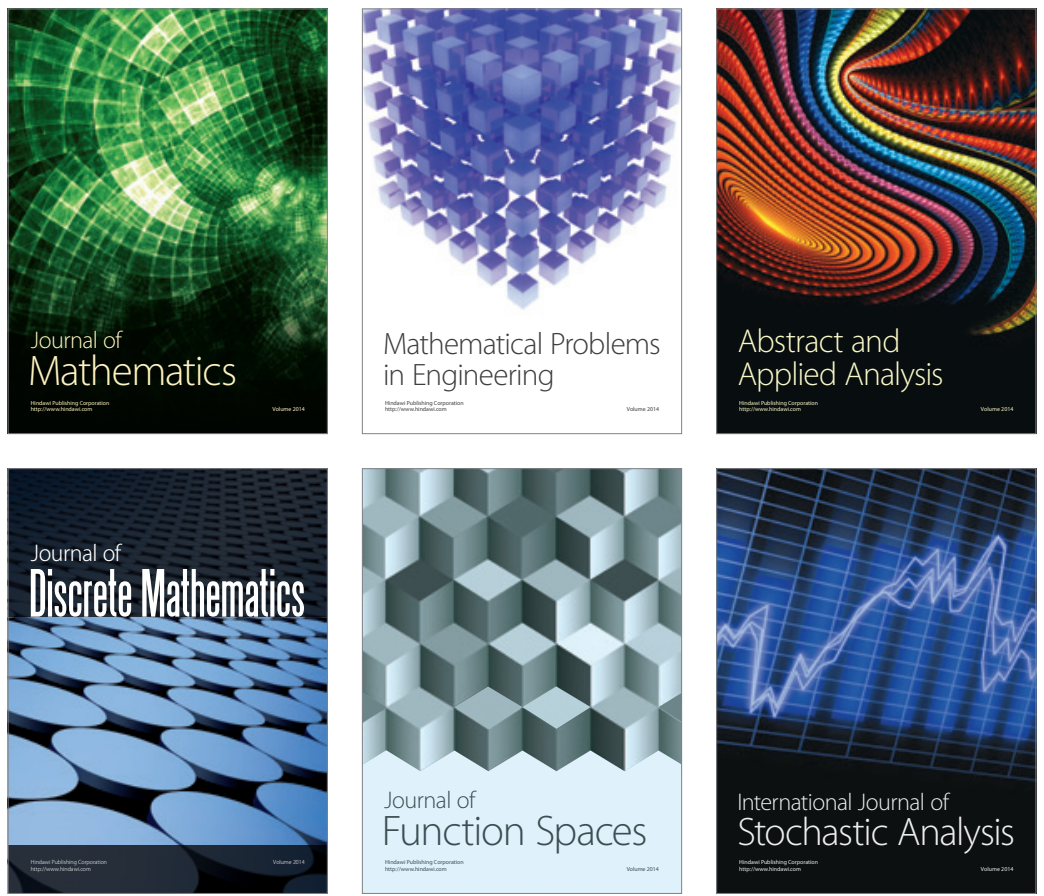

Journal of

Function Spaces

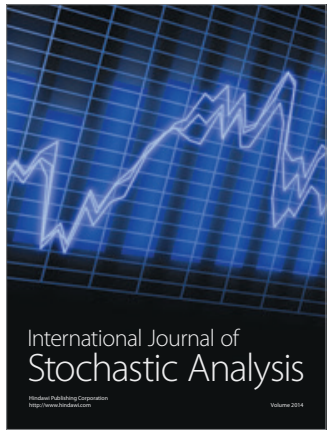

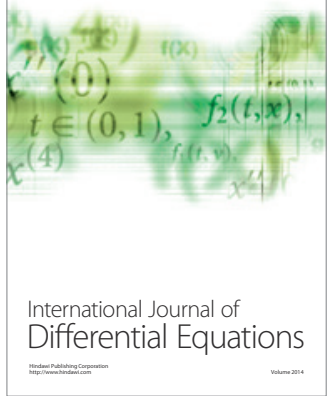
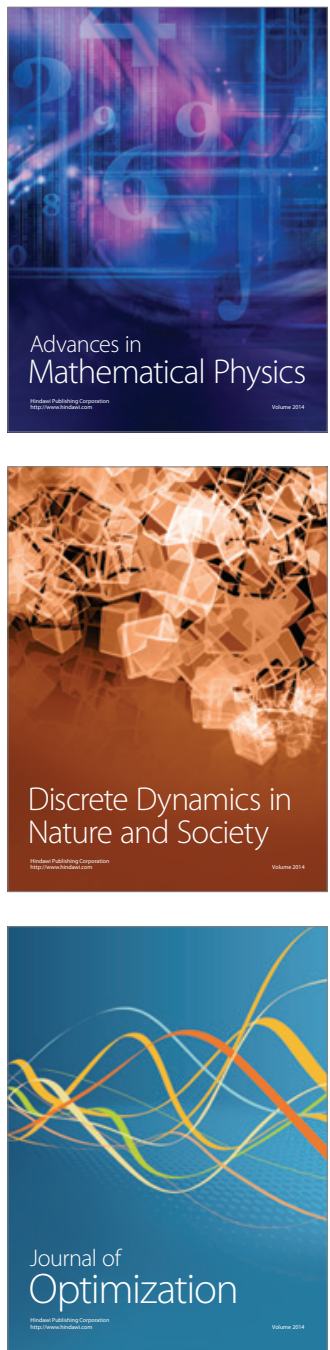